OPEN ACCESS

Edited by:

Jaap Joles,

Utrecht University, Netherlands

Reviewed by:

Rohit Ramchandra,

The University of Auckland,

New Zealand

Rajesh Mohandas,

University of Florida, United States

*Correspondence:

Markus P. Schlaich

markus.schlaich@uwa.edu.au

Specialty section:

This article was submitted to Renal and Epithelial Physiology,

a section of the journal

Frontiers in Physiology

Received: 02 May 2019

Accepted: 09 December 2019

Published: 14 January 2020

Citation:

Kiuchi MG, Ho JK, Nolde JM,

Gavidia LML, Carnagarin R, Matthews VB and Schlaich MP (2020)

Sympathetic Activation in Hypertensive Chronic Kidney Disease - A Stimulus for Cardiac Arrhythmias and Sudden Cardiac Death? Front. Physiol. 10:1546. doi: 10.3389/fphys.2019.01546

\section{Sympathetic Activation in Hypertensive Chronic Kidney Disease - A Stimulus for Cardiac Arrhythmias and Sudden Cardiac Death?}

\author{
Márcio Galindo Kiuchi' ${ }^{1}$ Jan K. Ho ${ }^{1}$, Janis Marc Nolde ${ }^{1}$, Leslie Marisol Lugo Gavidia', \\ Revathy Carnagarin', Vance B. Matthews ${ }^{1}$ and Markus P. Schlaich ${ }^{1,2,3 *}$
}

'Dobney Hypertension Centre, School of Medicine - Royal Perth Hospital Unit/Medical Research Foundation, The University of Western Australia, Perth, WA, Australia, ${ }^{2}$ Departments of Cardiology and Nephrology, Royal Perth Hospital, Perth, WA, Australia, ${ }^{3}$ Neurovascular Hypertension \& Kidney Disease Laboratory, Baker Heart and Diabetes Institute, Melbourne, VIC, Australia

Studies have revealed a robust and independent correlation between chronic kidney disease (CKD) and cardiovascular (CV) events, including death, heart failure, and myocardial infarction. Recent clinical trials extend this range of adverse CV events, including malignant ventricular arrhythmias and sudden cardiac death (SCD). Moreover, other studies point out that cardiac structural and electrophysiological changes are a common occurrence in this population. These processes are likely contributors to the heightened hazard of arrhythmias in CKD population and may be useful indicators to detect patients who are at a higher SCD risk. Sympathetic overactivity is associated with increased CV risk, specifically in the population with CKD, and it is a central feature of the hypertensive state, occurring early in its clinical course. Sympathetic hyperactivity is already evident at the earliest clinical stage of CKD and is directly related to the progression of renal failure, being most pronounced in those with end-stage renal disease. Sympathetic efferent and afferent neural activity in kidney failure is a crucial facilitator for the perpetuation and evolvement of the disease. Here, we will revisit the role of the feedback loop of the sympathetic neural cycle in the context of CKD and how it may aggravate several of the risk factors responsible for causing SCD. Targeting the overactive sympathetic nervous system therapeutically, either pharmacologically or with newly available device-based approaches, may prove to be a pivotal intervention to curb the substantial burden of cardiac arrhythmias and SCD in the high-risk population of patients with CKD.

Keywords: chronic kidney disease, sympathetic nervous system, hypertension, left ventricular hypertrophy, sudden cardiac death, ventricular remodeling, renal denervation 


\section{INTRODUCTION}

The prevalence of chronic kidney disease (CKD) is $\sim 8-12 \%$ in most countries becoming a significant public issue across the globe, and it can progress to end-stage renal disease (ESRD) and renal replacement therapy (RRT). In these patients, the most typical cause of death is by far cardiovascular (CV) complications. Congestive heart failure (HF) and cardiac arrhythmias, in particular, are highly prevalent and a common reason for hospitalization (Kiuchi and Mion, 2016; Kusumoto et al., 2018). As the renal impairment has been considered an independent hazard for sudden cardiac death (SCD), several cohort studies and clinical trials have used it as a well-defined endpoint (Kiuchi and Mion, 2016; Kusumoto et al., 2018).

\section{SUDDEN CARDIAC DEATH, CHRONIC KIDNEY DISEASE, AND EPIDEMIOLOGY}

\section{Chronic Kidney Disease}

Clinical trials evaluating the effectiveness of automatic implantable cardioverter-defibrillators (ICDs) have demonstrated the high hazard of SCD in the CKD population. These findings are supported by the 2018 United States Renal Data System (USRDS) (Table 1; United States Renal Data System, 2018).

On optimized pharmacological therapy, every $10 \mathrm{~mL} / \mathrm{min} / 1.73 \mathrm{~m}^{2}$ glomerular filtration rate fall accounted for an increase of SCD risk by 17\% (Goldenberg et al., 2006). Given the relevance and prognostic implications of HF in this population, the existence or non-existence of LV systolic dysfunction (i.e., "systolic" HF with reduced ejection fraction, "diastolic" HF with preserved ejection fraction, or unspecified) was meticulously examined (Figure 1). All types of HF were more typical amongst CKD subjects in comparison to those without CKD. The proportional ratio of individuals having CKD

TABLE 1 | Prevalence of HF, SCD, and VA and annual incidence of cardiovascular procedures.

\begin{tabular}{|c|c|c|c|c|c|c|}
\hline \multicolumn{7}{|c|}{$\%$ Patients } \\
\hline & \#Patients & Overall & $66-69$ & $70-74$ & $75-84$ & $\geq 85$ \\
\hline \multicolumn{7}{|c|}{ Heart failure } \\
\hline Non-CKD & $1,086,232$ & 6.1 & 3.1 & 4.3 & 7.2 & 13.3 \\
\hline Any CKD & 175,840 & 25.9 & 18.3 & 20.1 & 25.7 & 36.1 \\
\hline \multicolumn{7}{|l|}{ SCD/VA } \\
\hline Non-CKD & $1,086,232$ & 1.4 & 1.0 & 1.4 & 1.8 & 1.8 \\
\hline Any CKD & 175,840 & 4.1 & 3.4 & 3.9 & 4.4 & 4.3 \\
\hline \multicolumn{7}{|c|}{ ICD/CRT-D } \\
\hline Non-CKD & 66,426 & 0.6 & 0.6 & 0.8 & 0.6 & 0.3 \\
\hline Any CKD & 45,552 & 1.0 & 1.5 & 1.4 & 1.1 & 0.6 \\
\hline
\end{tabular}

$C K D$, chronic kidney disease; CRT-D, cardiac resynchronization therapy with defibrillator; HF, heart failure; ICD, implantable cardioverter-defibrillator; $S C D$, sudden cardiac death, VA, ventricular arrhythmias. Adapted from 2018 United States Renal Data System annual data report (United States Renal Data System, 2018). and systolic HF concomitantly was demonstrated to be greater than for diastolic HF; also, the prevalence increased with CKD progression (United States Renal Data System, 2018).

The "Comparison of Medical Therapy, Pacing, and Defibrillation in Heart Failure Trial" showed late stages HF patients with intraventricular electrical conduction disorders (e.g., bundle branch block) had significant reductions in death and hospitalization rates after cardiac resynchronization therapy (Bristow et al., 2004). In addition, existing renal dysfunction raised the harm for SCD by $67 \%$ during the 16 -months of follow-up (Saxon et al., 2006). HF reduced survival rates amongst CKD and non-CKD groups (Figure 2), although this was more pronounced in the former ( $p$-value for interaction $<0.0001$ ) (United States Renal Data System, 2018). After 2 years, the adjusted survival probability was $77.8 \%$ for patients with concomitant $\mathrm{HF}$ and CKD, $84.6 \%$ for HF subjects without CKD, 90.2\% for non-HF individuals with CKD, and $93.7 \%$ for those without CKD and HF (United States Renal Data System, 2018). Analyzing the 2-year survival of patients with HF according to their CKD stages the survival rates fell with further progression of renal disease (stages $1-2=70.2 \%, 3=65.8 \%$, and $4-5=55.7 \%$, respectively). A similar 2-year survival trend was observed in patients with CKD who presented with ventricular arrhythmias (VAs). Survival rates of healthy individuals $(86 \%)$ were higher than those for patients with CKD $(68.8 \%)$. Further deterioration of kidney function was associated with lower survival rates (Stage $1-2=75.4 \%$, Stage $3=68.7 \%$, and Stage $4-5=57.9 \%$ ) (United States Renal Data System, 2018). Furthermore, a correlation between SCD and renal damage was shown in non-HF individuals with moderate CAD (Deo et al., 2008; Pun et al., 2009).

Several investigations have attempted to outline SCD hazard amongst CKD subjects taking into account the influences of confounding prevalent $\mathrm{CV}$ diseases. A community study, including 4,465 participants without any previous history of myocardial infarction (MI) or HF demonstrated that the SCD incidence was 2.5 folds higher in those who had advanced CKD (Saxon et al., 2006). The SCD hazard was doubled in participants with "pre-clinical renal disease" (Deo et al., 2010) (defined as estimated glomerular filtration rate: eGFR $>60 \mathrm{~mL} / \mathrm{min} / 1.73 \mathrm{~m}^{2}$ and Cystatin $C$ level $\geq 1.0 \mathrm{mg} / \mathrm{L}$ ) matched to those with unaltered renal function (defined as eGFR $>60 \mathrm{~mL} / \mathrm{min} / 1.73 \mathrm{~m}^{2}$ and Cystatin $\mathrm{C}$ level $<1.0 \mathrm{mg} / \mathrm{L}$ ). This suggests that even minor drops in the eGFR may raise SCD risk, particularly in the elderly (Deo et al., 2010).

\section{End-Stage Renal Disease}

In the current context, most CV deaths reported in ESRD are attributed to SCD (Levey et al., 1998). In this population, arrhythmic deaths and MI represent $22 \%$ of all deaths (Herzog et al., 2005). In a cohort of 1,041 hemodialysis patients, 658 deaths were reported over an 8-year followup period. Amongst them, 146 deaths were attributed to SCD (rate of $1.8 \%$ per year) (Parekh et al., 2008). Similarly, a significant frequency of SCD at 5 years of follow-up (4.9\% per year) was reported by a Chinese prospective trial comprising 230 participants, in which reduced LVEF and 


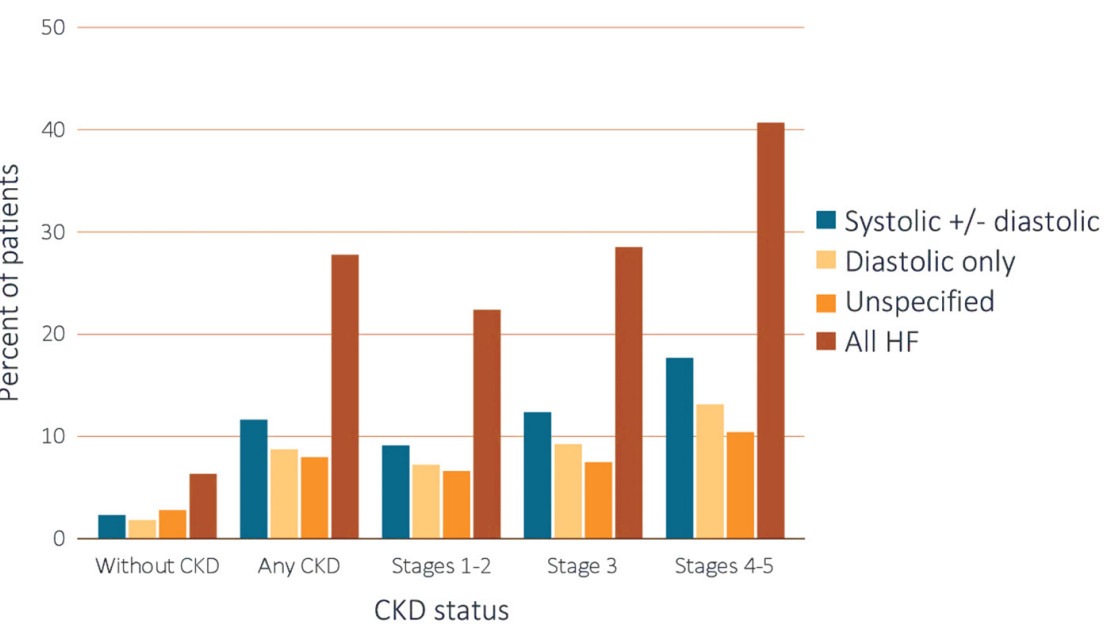

FIGURE 1 | Heart failure in healthy and CKD subjects. CKD, chronic kidney disease; HF, heart failure. Adapted from 2018 United States Renal Data System annual data report (United States Renal Data System, 2018). Reproduced with permission.

widened pulse pressure were considered predictors of SCD (Wang et al., 2010).

Congestive $\mathrm{HF}$ is commonly characterized by sustained renin-angiotensin-aldosterone system (RAAS) and sympathetic nervous system (SNS) overactivation, promoting higher $\mathrm{Na}^{+}$ and water retention with increased vascular tone and structural cardiac, renal and vascular remodeling. On the heart level, this resulting increase in LV and atrial pressure stimulates natriuretic peptide synthesis and secretion. Moreover, natriuretic peptides exert a key function in regulating blood pressure and extracellular fluid volume (Volpe et al., 2016). In non-adjusted and completely adjusted analyses, N-terminal pro-hormone of brain natriuretic peptide (NT-proBNP) correlated strongly with SCD hazard (Kruzan et al., 2016). When assessed as a continuous parameter, SCD hazard rose by $27 \%$ at every 2 -fold NT-proBNP growth. In categorical analyses, SCD hazard was 3 -fold greater in the NT-proBNP top tertile $(>7,350 \mathrm{pg} / \mathrm{mL})$

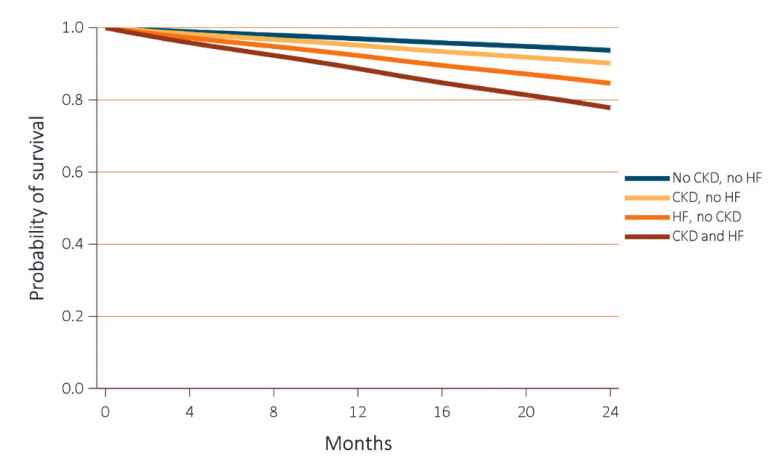

FIGURE 2 | Adjusted survival of subjects by CKD and heart failure status. Survival was adjusted for age, sex, race, diabetic, and hypertension status. CKD, chronic kidney disease; HF, heart failure. Adapted from 2018 United States Renal Data System annual data report (United States Renal Data System, 2018). Reproduced with permission. in comparison to its bottom tertile $(<1,710 \mathrm{pg} / \mathrm{mL})$. There was a trend for an association of elevated troponin I (cTnI) levels with a heightened risk of SCD in entirely adjusted models. Sensitivity assessments by comparing hazard analyses demonstrated analogous outcomes. Enhancement in hazard prediction by cardiac biomarkers addition to typical hazard factors seemed to be higher with NT-proBNP (concordance statistic for 3-year hazard: 0.810 ; 95\% confidence interval, $0.757-$ 0.864 ; and continuous net reclassification improvement: 0.270 ; 95\% confidence interval, 0.046-0.495) compared to cTnI (Kruzan et al., 2016). The presence of elevated levels of cardiac biomarkers has not only been associated with higher SCD occurrence but also with reversible myocardial stunning. An observational cohort study of 70 prevalent hemodialysis patients found that myocardial stunning was common during dialysis (64\%) and was related to increased relative mortality and development of low LVEF after 1 year (Burton et al., 2009). Even though a reduced LVEF in the non-dialysis population is a hazard element for SCD, it does not appear to be as relevant as in the ESRD population. In a review of 80 ESRD deaths that occurred secondary to SCD, a LVEF $\leq 35 \%$ was only evident in one-fourth of the patients (Bleyer et al., 2006).

The prevalence of HF, SCD and the occurrence of VAs and ICD/CRT-D implantation were analyzed in ESRD patients on RRT in the 2018 USRD annual report, and the findings are summarized in Table 2 (United States Renal Data System, 2018). The 2-year survival rates of ESRD adult patients with and without HF were 66.0 and $93.4 \%$, respectively. The respective rates in the presence and absence of SCD and VAs were 55.3 and $77.2 \%$. When ICD/CRT-D were implanted in these patients, their 2-year survival rate was inferior (48.1\%) compared to subjects who did not undergo device implantation (62.9\%) (United States Renal Data System, 2018). This, however, could perhaps be attributed to the severity of the underlying CV disease, as ICD/CRT-D procedures are performed mostly in late stages of $\mathrm{HF}$. 
TABLE 2 | Prevalence of HF, SCD, and VA and annual incidence of cardiovascular procedures in End-stage renal disease individuals.

\begin{tabular}{lccccc}
\hline \multicolumn{5}{c}{ \% Patients } \\
\hline & \#Patients & Overall & $\mathbf{6 6 - 6 9}$ & $\mathbf{7 0 - 7 4}$ & $\geq \mathbf{7 5}$ \\
\hline Heart failure & & & & & \\
Hemodialysis & 218,720 & 40.4 & 28.3 & 38.5 & 44.7 \\
Peritoneal dialysis & 22,023 & 28.3 & 19.9 & 27.6 & 32.7 \\
Transplant & 75,313 & 14.4 & 6.0 & 12.4 & 19.5 \\
SCD/VA & & & & & \\
Hemodialysis & 218,720 & 4.8 & 2.9 & 4.6 & 5.7 \\
Peritoneal dialysis & 22,023 & 4.6 & 2.1 & 4.4 & 5.8 \\
Transplant & 75,313 & 2.0 & 0.6 & 1.6 & 3.1 \\
ICD/CRT-D & & & & & \\
Hemodialysis & 88,377 & 0.9 & 0.9 & 1.0 & 1.0 \\
Peritoneal dialysis & 6,181 & 1.1 & 0.6 & 1.2 & 1.3 \\
Transplant & 10,851 & 0.8 & 0.1 & 0.7 & 0.9 \\
\hline
\end{tabular}

CRT-D, cardiac resynchronization therapy with defibrillator; HF, heart failure; $I C D$, implantable cardioverter-defibrillator; SCD, sudden cardiac death; VA, ventricular arrhythmias. Adapted from 2018 United States Renal Data System annual data report. Adapted from 2018 United States Renal Data System annual data report (Kusumoto et al., 2018).

Cardiac arrhythmia/arrest accounted for $\approx 40$ and $17 \%$ of identified causes of death amongst individuals on dialysis and transplant recipients, respectively (Figure 3; United States Renal Data System, 2018). The cause of death was not available or unidentified for 27 and $74 \%$ of dialysis patients and transplant participants recruited for the study, respectively. CV causes (arrhythmias, cardiac arrest, congestive HF, acute $\mathrm{MI}$, and coronary atherosclerosis) were responsible for 48 and $28 \%$ of deaths amongst subjects on dialysis or transplant receivers, respectively (United States Renal Data System, 2018).

In the context of ESRD CV disease is known to contribute to rising mortality rates in the short and long-term. USRDS data (Herzog et al., 1998) demonstrated, after 1 year of followup, a mortality rate of $60 \%$ in patients on long-term dialysis post-acute MI (United States Renal Data System, 2018). In general, the presence of CV disease in ESRD patients significantly worsens their survival rates. Finally, the robust relationship between SCD and ESRD also spreads to the pediatric population. A retrospective assessment of USRDS data comprising $\sim 1,400$ deaths amongst ESRD individuals aged up to 30 years showed that cardiac arrest and arrhythmias accounted for most deaths associated with cardiac causes ( $>2 \% /$ year) (Parekh et al., 2002). These findings indicate that mechanisms other than those associated with CAD and/or HF prompt fatal arrhythmias in subjects with ESRD.

\section{PATHOPHYSIOLOGIC MECHANISMS CONTRIBUTING TO HIGH RISK FOR ARRHYTHMIAS}

Sudden cardiac death pathophysiology has been described as multifaceted; combinations of various factors can result in electrical conduction volatility and VAs, followed by hemodynamic collapse. Understanding this mechanism may

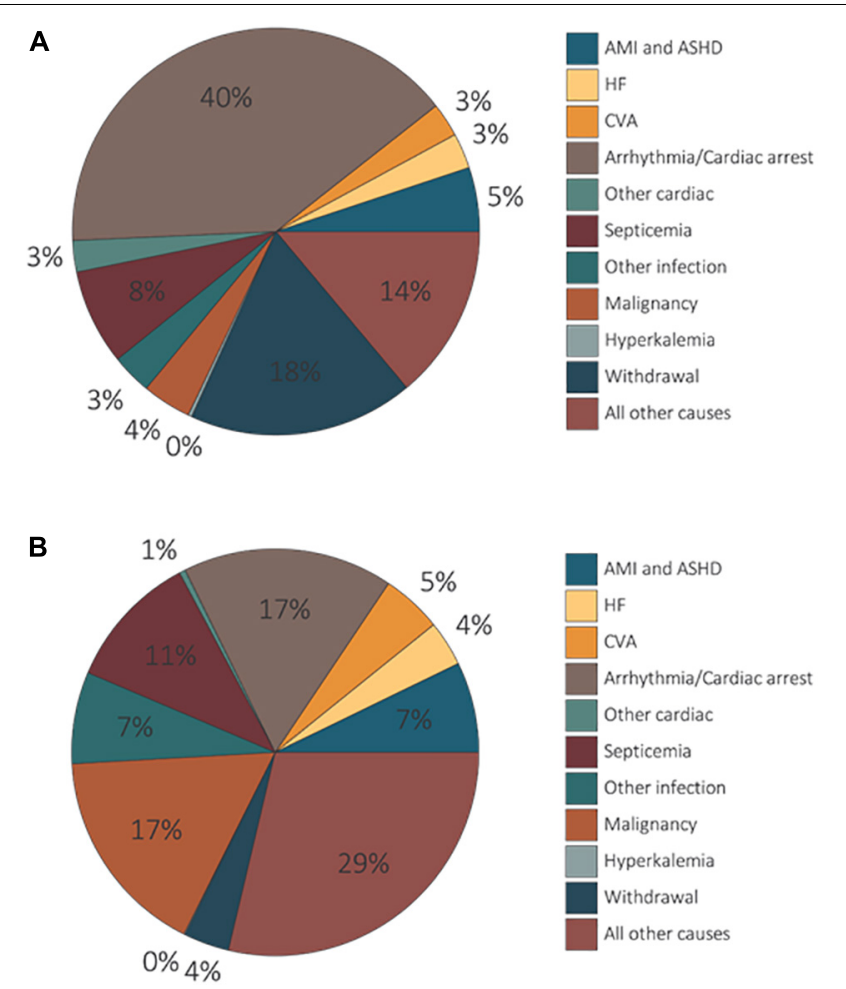

FIGURE 3 | Unadjusted percentages of deaths by cause, modality amongst dialysis patients and transplant recipients. Dialysis patients' data exclude missing/unknown causes of death (A). Transplant patients' denominator excludes missing/unknown causes of death (B). AMI, acute myocardial infarction; ASHD, atherosclerotic heart disease; CHF, congestive heart failure; CVA, cerebrovascular accident (United States Renal Data System, 2018). Reproduced with permission.

assist in identifying the time point at which the interaction between a prompting incident and a present source is risky. Remodeling of the structure and electrophysiologic properties of the heart, fibrosis, coronary artery calcification, autonomic imbalance, and volume and electrolyte changes are all considered contributors to this scenario.

\section{Structural Remodeling}

Renal impairment provokes cardiac remodeling including LV hypertrophy (LVH) and its fibrosis. Clinical evidence revealed an independent correlation between LVH and CKD in subjects with mild to moderate reduction in eGFR (Levin et al., 1999; Paoletti et al., 2005; Moran et al., 2008; Cerasola et al., 2010). Notably, the frequency of LVH increases with worsening of renal function. Furthermore, fibrosis and non-ischemic cardiomyopathy were demonstrated by magnetic resonance imaging (MRI) in dialysis patients (Mark et al., 2006). Hypertension, diabetes mellitus, and anemia were common co-morbidities and may partially explain the LV remodeling that occurs (Schroeder et al., 1997; Hunter and Chien, 1999; Cioffi et al., 2011). Mechanistically, activation of growth factors, proto-oncogenes, and cytokines, together with increased norepinephrine and angiotensin II 
plasma concentrations are likely contributors through their welldefined effects on cardiac structure, from hypertrophy to fibrosis and apoptosis (Mall et al., 1990; Amann et al., 1998). A higher hazard of sustained ventricular tachycardia (VT) and SCD susceptibility has been associated with those structural changes per se (Haider et al., 1998; Yan et al., 2006; Schmieder et al., 2007; Roes et al., 2009; Reinier et al., 2011).

Chronic kidney disease is also linked to peripheral vascular disease (Pai and Giachelli, 2010; Briet et al., 2011; Hu et al., 2011; Shroff and Shanahan, 2011). The reduction of vascular elasticity is correlated with worsening eGFR and endothelial dysfunction. An inadequate endothelium-dependent vasodilator response can already be detected in mild renal disease (Perticone et al., 2004, 2010). As a consequence of vessel remodeling and sclerosis, coronary perfusion reserve is affected and can raise the risk of ischemic events (Kingwell et al., 2002) and arrhythmias. In ESRD, vascular remodeling is more apparent as calcium-phosphate accumulation, which may additionally provoke vascular integrity impairment (Schlieper et al., 2010). Excessive phosphate levels and enhanced calcium-phosphate product have been demonstrated to raise, SCD risk from 20 to 30\% (Ganesh et al., 2001).

\section{Electrophysiological Alterations}

Structural alterations can affect the myocardial electrophysiology. Myocardial fibrosis changes the tissue structure slowing down stimulus conduction through the fibers (Waldo et al., 1983), which can sustain re-entrant arrhythmias (e.g., VT) (Yan et al., 2006; Schmidt et al., 2007; Roes et al., 2009). Altered cardiac conduction can retard the activation of the ventricles and thereby, in the last segment of the QRS complex, produce late action potentials. They are low amplitude signals and were identified in $25 \%$ of patients on RRT (Morales et al., 1998). Also, the non-homogeneous retrieval of the excitability of the ventricles was reported by studies evaluating QT interval dispersion; it is mainly increased in the post-dialysis period (Lorincz et al., 1999; Morris et al., 1999; Patel et al., 2011) and may reflect a higher vulnerability to VAs (Kiuchi and Mion, 2016). Post-evaluation by a 24-h Holter monitoring revealed that $>90 \%$ of RRT patients presented with abnormal T-wave alternans (TWA) throughout $24 \mathrm{~h}$ (Secemsky et al., 2011) and that dialysis sessions could provoke alterations in TWA (Friedman et al., 2007; Green et al., 2012). A study comprising 48 participants demonstrated that TWA rose throughout dialysis sessions returning to basal levels after dialysis. However, the investigators did not find any correlation with electrolyte levels, LV structure and function, major adverse CV events, or mortality (Green et al., 2012).

Malignant arrhythmias and SCD may also be associated with dialysis frequency in ESRD individuals. After a lengthy interdialytic period, a failure to keep the desirable homeostasis may occur predisposing patients to harmful events (Kiuchi and Mion, 2016). Undeniably, VAs and SCD often occur on Mondays and Tuesday's after the long dialysis-free interval over the weekend and within $12 \mathrm{~h}$ subsequent to the HD sessions beginning (Bleyer et al., 1999, 2006; Perl and Chan, 2006; Foley et al., 2011; Kumar et al., 2016) suggesting that BP changes and variations of electrolyte- and volume- homeostasis can provoke arrhythmias.

Myocardial scars create areas of heterogeneous electricity conveyance predisposing to re-entrant arrhythmias, specifically in the context of renal dysfunction initiated either automatically or elicited by different regions within the myocardium (Brotman et al., 2010). The association of ESRD with increased sympathetic nerve discharge rates and the susceptibility of abnormal rhythms to adrenergic activity have been shown in some human studies. These are mediated partially by afferent discharges arising from the kidney (Converse et al., 1992; Svarstad et al., 2001; Hausberg and Grassi, 2007) providing a potential basis for a high incidence of ventricular ectopic beats (VEBs) in $>75 \%$ of patients with ESRD for the period of and post to dialysis sessions (Gruppo Emodialisi E Patologie Cardiovascolari, 1988). Sympathetic activity in these subjects is perhaps more likely than in other patient cohorts to results in adverse consequences (Zoccali et al., 2002).

\section{SYMPATHETIC OVERACTIVITY IN HYPERTENSION AND CKD}

In patients with $\mathrm{CKD}$, sympathetic hyperactivity raises the $\mathrm{CV}$ risk and exerts a critical role in increasing blood pressure. Also, sympathetic overdrive can already be found in the earliest phases of CKD (Grassi, 2009, 2010; Paton and Raizada, 2010). In both hypertension and CKD, several mechanisms contribute to sympathetic excitation, including reflex and neuro-humoral pathways (McGrath et al., 1978; Grassi, 2009, 2010). Sympathetic overactivity has been correlated to CKD evolvement and can be triggered by several types of renal damage (McGrath et al., 1978; Neumann et al., 2004; Schlaich et al., 2009a; Grassi et al., 2012). Afferent and efferent nerves surrounding renal vessels, tubules, the pelvis, and glomeruli supply renal innervation. It facilitates the interconnection within the neuro-cardio-renal axis (Drukker et al., 1987; Barajas et al., 1992; Kumagai et al., 2012; Mahmoodi et al., 2012; Mulder et al., 2013) through a two-way neural path to convey afferent and efferent sympathetic impulses to and from the brain, respectively (Guertzenstein and Silver, 1974; Campese and Kogosov, 1995; Garthwaite and Boulton, 1995; Ye et al., 1997; Zanzinger, 2002; Kimura et al., 2005; Kumagai et al., 2012). Increased sympathetic tone, via renal efferent nerves, modifies tubular reabsorption of $\mathrm{Na}^{+}$and $\mathrm{H}_{2} \mathrm{O}$ with subsequent fluid retention, renal blood flow decrease, and RAAS stimulation (DiBona and Kopp, 1997; Krum et al., 2009; Schlaich et al., 2009a,b; Grassi et al., 2012). The central integration of afferent renal stimulus to regulate primary sympathetic discharge completes the feedback loop (Campese and Kogosov, 1995; DiBona and Kopp, 1997; Ye et al., 1997; Kumagai et al., 2012).

Hypertensive states, other CV diseases, CKD and ESRD, are often characterized by augmented renal sympathetic nerve activity (RSNA) (Lundin et al., 1984; Grassi et al., 1998; Esler et al., 2003; Campese et al., 2006) as demonstrated by high levels of muscle sympathetic nerve activity (MSNA) documented in every stage of human hypertension (Grassi et al., 1998). High levels of renal norepinephrine spillover have been described in 
human hypertension (Esler et al., 2003) and increased renal sympathetic nerve firing rates in preclinical models (Lundin et al., 1984). Meta-analyses have revealed that worsening in eGFR is an independent CV hazard (Mahmoodi et al., 2012) and that sympathetic activation is linked to poorer CV outcomes (Zoccali et al., 2002; Grassi, 2009, 2010; Grassi et al., 2012). There is clear data that hypertensive patients with mild renal damage have significant elevated MSNA in comparison to hypertensive individuals with normal renal function and to normotensive populations (Figure 4; Tinucci et al., 2001). A close relation between sympathetic activation and gradual renal function decline is evident.

Afferent sensory renal nerves are crucial to modulate SNS activity, as has been elegantly shown in studies conducted in ESRD and post-renal transplant patients. Increased SNS activity persists in ESRD patients despite hemodialysis and even after renal transplantation due to the remaining native kidneys (Converse et al., 1992). Indeed, BP and MSNA can be normalized by removal of the native kidneys. Consequently, focusing on the renal sympathetic nerves as a therapeutic target is a reasonable approach to treat hypertension and states of renal damage to prevent the progression of renal impairment (Barnett et al., 2014).

Accumulating evidence suggests a potential role of gut dysbiosis in the pathophysiological mechanisms involved in hypertension and $\mathrm{CKD}$ via the neuroendocrine regulation of immunity. The gut microbiome sustains intricate communication with vital organs (e.g., immune system, bone marrow, blood vessels, kidneys, and central and autonomic nervous system: ANS) to control cardiometabolic homeostasis (Bercik et al., 2011; Bravo et al., 2011; Karbach et al., 2016; Rooks and Garrett, 2016; Dinan and Cryan, 2017; Evenepoel et al., 2017; Josefsdottir et al., 2017). In addition to the endocrine

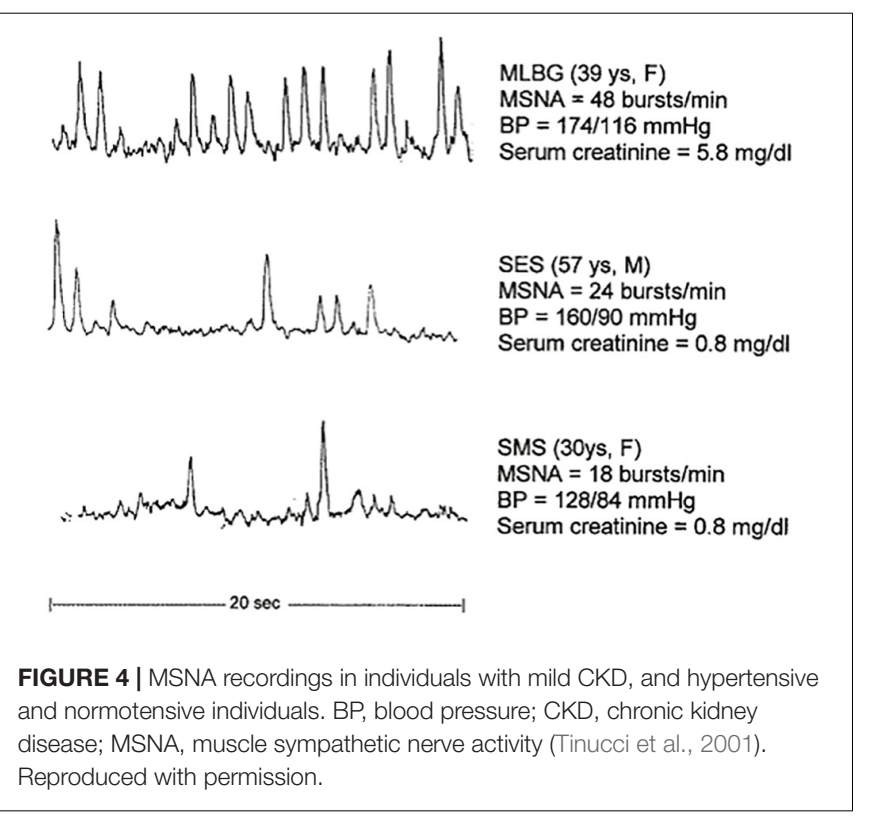

effect, the gut microbiome also exerts a paracrine influence via its metabolites (Akchurin and Kaskel, 2015; Santisteban et al., 2015; Shankland and Jefferson, 2017; Carnagarin et al., 2019). Gut dysbiosis may play an important role in the onset and advance of CKD. Gut dysbiosis elicits immune-mediated inflammatory responses affecting regulatory brain nuclei and its relations to the SNS and thereby the kidneys (Carnagarin et al., 2019). This provokes a positive feedback loop where the resulting sympathoexcitation further promotes gut dysbiosis and increases gut permeability allowing the escape of toxic metabolites in the circulation as seen in CKD (Vanholder et al., 2003; Martinez et al., 2005; Jourde-Chiche et al., 2009; Vaziri, 2012; Sabatino et al., 2015).

\section{THERAPEUTIC TARGETING OF SNS ACTIVATION}

Given the great importance of SNS activation in hypertension and $\mathrm{CKD}$ and its close association with adverse CV consequences, including SCD, therapeutic targeting of the SNS at various levels is expected to confer clinical benefit. A conventional approach is the blockade of peripheral $\beta$-receptors, and more recently, direct interference with renal afferent and efferent nerves through RDN has shown promising results.

\section{$\beta$-Blockers}

The anti-arrhythmic effectiveness of $\beta$-blockers is based on the competitive $\beta$-adrenoreceptor block of pro-arrhythmic properties mediated by the SNS, including decelerating of sinus frequency and probably the inhibition of additional $\mathrm{Ca}^{2+}$ discharge via the RyR2 channels. VEBs and VAs suppression, as well as SCD rate reduction, have been demonstrated with $\beta$-blockers particularly in HF (Krittayaphong et al., 2002; Prystowsky et al., 2012; Shinohara et al., 2017). $\beta$-blockers are considered efficient and safe anti-arrhythmic drugs and represent an established pharmacological antiarrhythmic therapy. Generally, VAs management and SCD prevention utilise $\beta$-blockers as the pillar for their treatment (Priori et al., 2016).

\section{Renal Denervation}

Renal denervation is a device-based technique to directly modulate efferent and afferent nerves connecting both kidneys and central integrative structures in the brain. In resistant hypertensive patients, a marked BP-lowering effect and a fast decrease in the activity of single fibre sympathetic nerve units were noticed post-RDN (Hering et al., 2013). Moreover, sympathetic overactivity and RAAS disruption are likely to benefit this population. RDN has been proved to be safe in all studies carried out thus far, and may be of specific benefit in hypertensive CKD subjects (Hering et al., 2012; Kiuchi et al., 2013; Luo et al., 2013; Schlaich et al., 2013). Similarly, ESRD subjects with poorly controlled hypertension had a continuous systolic office BP-lowering effect and an important fall in MSNA over 12-months post-RDN, without safety concerns (Schlaich et al., 2013). 
Aside from the improved BP control, the regression of hypertensive target organ damage is considered a good indicator of therapeutic efficiency. Indeed, structural and functional changes were noticed as assessed by echocardiography postRDN. This effect was also observed in $83 \%$ of the participants who were classified as "non-responders", as their BP-lowering effect was less than $10 \mathrm{mmHg}$ (Brandt et al., 2012). Direct modulation of SNS activity may have benefits beyond its impact on BP with implications for high-risk populations (Brandt et al., 2012; Kiuchi and Mion, 2016).

In another study (Mahfoud et al., 2014) 72 subjects with resistant hypertension underwent cardiac-MRI (55 of them underwent RDN, and 17 were controls) prior to and 6 months after RDN. A remarkable BP-lowering effect in both systolic and diastolic BP $(\sim 22 / 8 \mathrm{mmHg})$, as well as a reversal of the left ventricular remodeling (LV mass index regression of $7.1 \%$ ), were reported post-RDN. On the other hand, control subjects did not present any variation. After RDN, average LVEF significantly improved by $\approx 7 \%$. In this study, LV circumferential strain substituted diastolic function. Patients who were subjected to RDN had their circumferential strain significantly improved by $21 \%$, while control subjects did not experience this effect.

Doltra et al. (2014) prospectively assessed 23 resistant hypertensive patients who had undergone cardiac-MRI and $\mathrm{RDN}$. RDN led to a decrease in LVMI regardless of the BPlowering effect, suggesting that RDN may additionally reduce interstitial fibrotic tissue in the myocardium, regarding absolute collagen matter, because if the observed LVMI regression was exclusively owing to a reversal of myocyte hypertrophy, extracellular volume fraction would be expected to increase (Doltra et al., 2014). Whether this has a potential effect on the prognosis and the event reduction remains unknown. Besides, Perlini et al. (2005) did previously demonstrate in rodents that interstitial fibrosis in the myocardium provoked by hypertension improved after $\alpha$-adrenergic block or sympathectomy.

More recently, McLellan et al. (2015) collected 24-h ambulatory-blood-pressure (ABPM), echocardiograms, cardiacMRI and electrophysiological studies in 14 subjects presenting with resistant hypertension prior to and 6 months postRDN. After RDN, the average ABPM was reduced, while overall conduction velocity rose considerably, and conduction interval was reduced. Also, changes in conduction velocity and variations in average ABPM correlated positively. In an ovine model, those with chronic hypertension had left atrial remodeling on diverse time-domains and a strong association between electrophysiology properties and structure involved in the remodeling flow. These successive morphological modifications were linked to conduction abnormalities and resulted in greater atrial fibrillation inducibility and duration. Immediate antihypertensive therapy commencement may avoid the development of substrates able to maintain atrial fibrillation (Lau et al., 2010). A marked reduction in MRI derived LV mass and diffuse ventricular fibrosis was also observed (McLellan et al., 2015), in keeping with studies discussed above.

Likewise, one hundred consecutive resistant hypertensive subjects who were subjected to RDN and experienced an average office systolic BP fall $>10 \mathrm{mmHg}$ at 6 month post-RDN were studied by Dorr et al. (2015). Cardiac extracellular matrix and CV

\section{Kidney as Origin of Central Sympathetic Activity}

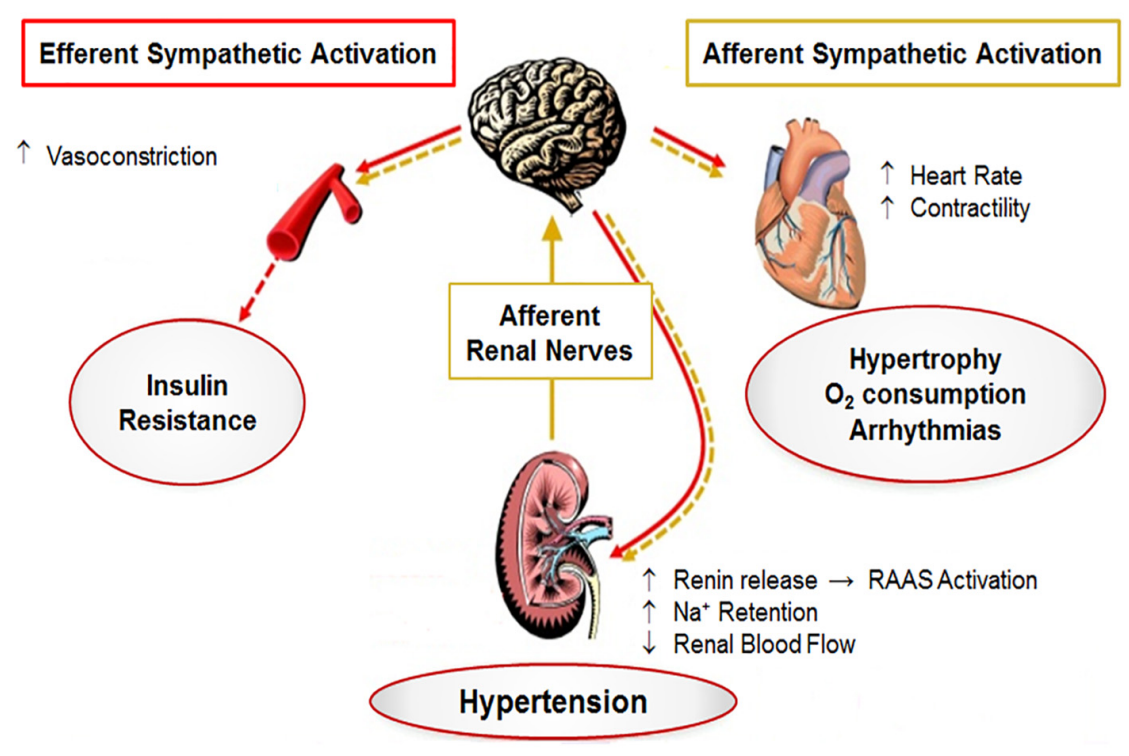

FIGURE 5 | Numerous types of renal injury can trigger increased afferent signaling, which is centrally integrated leading to increased sympathetic discharges to various organs, including the kidneys, and thereby stimulating renin secretion, $\mathrm{Na}^{+}$retention, and vasoconstriction. The increased sympathetic output is also pointed toward other relevant organs (e.g., the heart and peripheral vessels), which can result in adverse outcomes. RAAS, renin-angiotensin-aldosterone system; Na ${ }^{+}$ sodium; $\mathrm{O}_{2}$, oxygen. Adapted from Schlaich et al. (2009c). Reproduced with permission. 
fibrotic tissue reabsorption were assessed by different pro-peptide types before RDN and at 6 month follow-up through blood samples. A substantial office systolic BP drop was reported 6 months post-RDN. At this stage, the serum levels of propeptides were remarkably reduced compared to baseline in participants with an intensified collagen turnover. These results point to possible beneficial RDN effects on CV fibrosis in cohorts who have hypertensive heart disease and cardiac fibrosis.

Animal studies found sympathetic activation mitigation by RDN as assessed by renal catecholaminergic content reduction (Mahfoud et al., 2015). Moreover, RDN importantly improved LV longitudinal strain, reduced end-systolic volume and cardiac fibrosis, enhancing cardiac performance. Remarkably, neprilysin activity reduction and brain natriuretic peptide (BNP) level increases were shown after RDN (Ceia et al., 2002). In congestive HF, the excessive cardiac volume provokes BNP and atrial natriuretic peptide release, both of which have diuretic and cardioprotective effects (Stevens et al., 1996; da Silva and Aguiar, 2017). Heightened neprilysin activity was uncovered to worsen LV dysfunction, as it enzymatically degrades natriuretic and other bioactive peptides; and it is related to unfavorable outcomes. Therapeutically,
HF populations have enormously benefited from neprilysin inhibition by sacubitril/valsartan (McMurray et al., 2014). RDN induced neprilysin inhibition may, therefore, contribute to its apparent cardioprotective effects.

While these findings are promising and suggest that sympatho-inhibitory therapeutic approaches may have substantial therapeutic benefit, further in-depth investigation of how RDN may reduce the burden of HF and SCD in CKD is warranted as are larger-scale studies to confirm results obtained predominantly in selected cohorts without appropriate controls.

It is recognized that $\mathrm{CKD}$ progression can be slowed by a moderate control of BP. While RDN has been used predominantly to treat resistant hypertensive patients (Figure 5; Symplicity et al., 2010; Krum et al., 2014), it is likely of beneficial value in CKD. Indeed, RDN has demonstrated GFR improvement (Kiuchi et al., 2013, 2014; Delacroix et al., 2014) and reduction of albuminuria (Kiuchi et al., 2013, 2014; Ott et al., 2014; Schmieder et al., 2014), although these studies are limited by a short follow up period.

Kiuchi et al. (2016a) reported cardiac structural and functional enhancement, which were associated with eGFR improvement in a resistant hypertensive cohort with $\mathrm{CKD}$ at follow-up 6 month

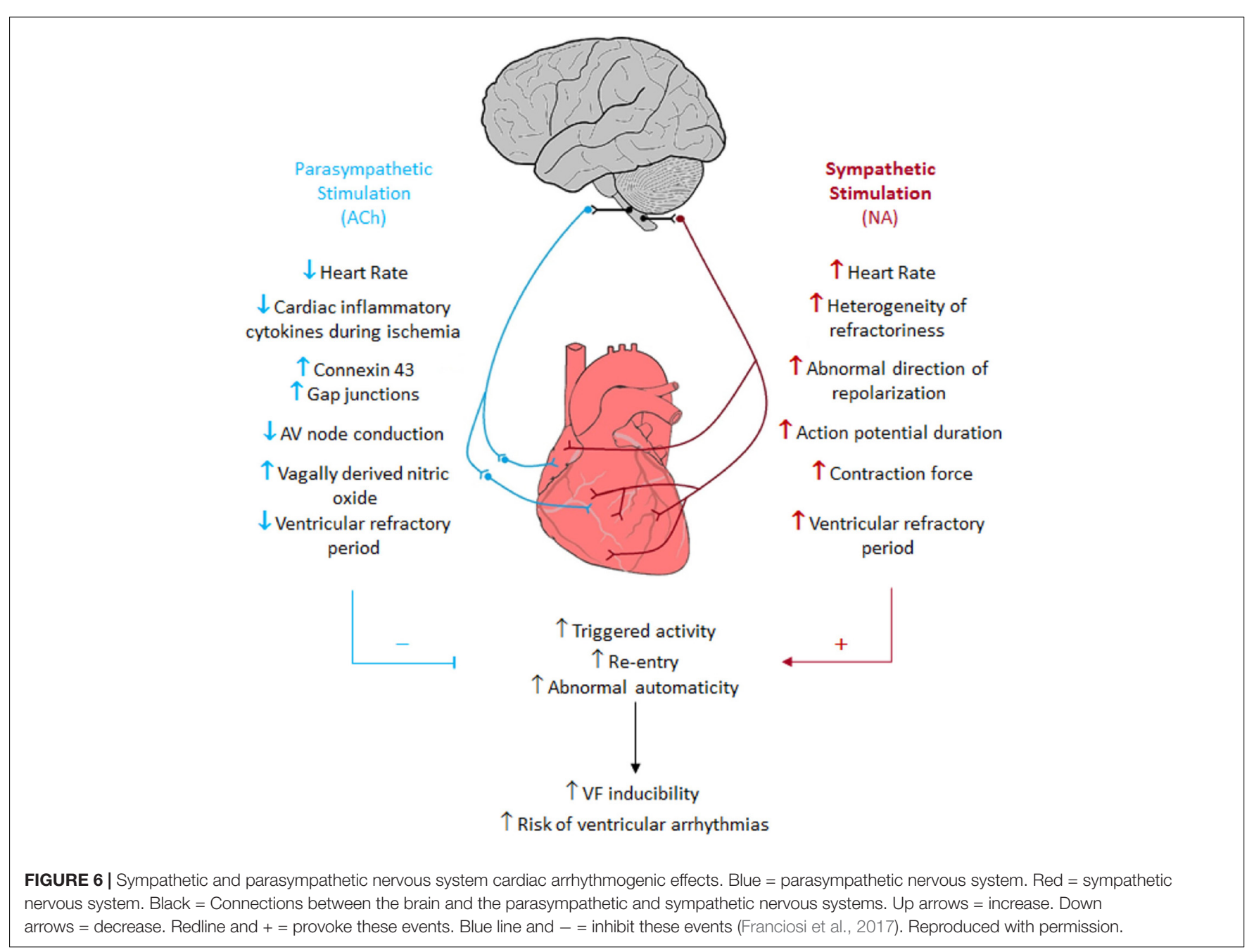


post-RDN. In this study, RDN improved echocardiographic parameters in patients with or without LVH (Kiuchi et al., 2016b). RDN was crucial in a series of cases comprising patients who had dilated cardiomyopathy and continuous episodes of VAs, as it impressively reduced the number of these arrhythmias and therefore the ICD shocks (Ukena et al., 2012). Growing data both from different case series (Remo et al., 2014; Armaganijan et al., 2015) and from a multicentre registry have shown favorable outcomes for anti-arrhythmic effects associated with RDN (Ukena et al., 2016). The limited data currently available suggest that RDN could be especially beneficial for HF subjects with VAs who are unresponsive to maximum $\beta$-blocker therapy and unsuitable for VT catheter-ablation. Alternatively, RDN may have an adjuvant role for those who will be subjected to catheterablation for refractory VAs.

In a cohort of HF subjects, NT-proBNP levels were reduced by $\mathrm{RDN}$, which was well tolerated and did not worsen the function of the heart and the kidneys (Hopper et al., 2017). Also, the proportion of refractory VAs and ICD shocks plunged post-RDN in another cohort with late stages of $\mathrm{HF}$ and CKD (Kiuchi et al., 2017).

The ANS imbalance plays a crucial role in advanced HF setting, which per se triggers and maintains VAs (Fukuda et al., 2015; Zipes, 2015). The hypersympathetic drive directed toward the heart can worsen other pre-existing conditions that contribute to VAs (e.g., ischemia, underlying rhythm and dilated cardiomyopathy) (Shen and Zipes, 2014; Fukuda et al., 2015). Unraveling the exact role of the ANS in the pathogenesis of VA will be rlevant for prevention and treatment of those arrhythmias (Ng, 2016; Franciosi et al., 2017; Figure 6).

Renal denervation may blunt sympathetic overactivity and arrhythmogenic foci, thereby potentially reducing arrhythmogenic activity. Preclinical data have shown remodeling of the stellate ganglion (SG) and the brain stem $\sim 2$ months post-RDN, likely medaited by afferent renal nerve signaling interruption (Tsai et al., 2017). Also, a reduction of ${ }^{18}$ FDGuptake, SG sympathetic traffic and atrial tachyarrhythmias were correlated to neural modifications of these structures. Therefore, such remodeling could at least in part explain the antiarrhythmic effects of RDN (Tsai et al., 2017). Even 1 year following a trauma, the central and peripheral nervous system may continue to impact on the damaged site and in distant zones of the brain (Bramlett and Dietrich, 2007). These gradual changes possibly underpin specific lasting effects following the primary damage, such as those provoked by RDN. In cats, roughly $10 \%$ of neurons located in renal sympathetic fibers

\section{REFERENCES}

Akchurin, O. M., Kaskel, F. (2015). Update on inflammation in chronic kidney disease. Blood Purif. 39, 84-92. doi: 10.1159/000368940

Amann, K., Kronenberg, G., Gehlen, F., Wessels, S., Orth, S., Munter, K., et al. (1998). Cardiac remodelling in experimental renal failure-an immunohistochemical study. Nephrol. Dial. Transplant. 13, 1958-1966. doi: $10.1093 / \mathrm{ndt} / 13.8 .1958$

Armaganijan, L. V., Staico, R., Moreira, D. A., Lopes, R. D., Medeiros, P. T., Habib, R., et al. (2015). 6-Month outcomes in patients with implantable cardioverterdefibrillators undergoing renal sympathetic denervation for the treatment of arise from the ganglia composing the thoracic chain (Meckler and Weaver, 1984). Due to these interconnections, SG cell death may occur retrogradely by RDN. This is supported by data showing that certain colorants applied to renal nerves resulted in bright labeling of the sympathetic cells located in the para- and pre-vertebral ganglionic chains (Ferguson et al., 1986; Gattone et al., 1986; Sripairojthikoon and Wyss, 1987). Usually, sympathetic preganglionic fibers reaching both SG run through the cervicothoracic spinal cord (Pilowsky et al., 1992), which hugely increases interconnection possibilities between these fibers and those arising from the kidneys. It is also possible that several different routes (i.e. carotid sinus) contribute with collapse between synapses (Tsai et al., 2017), as afferent renal nerve ganglionic cells situated in lumbar and thoracic dorsal root ganglia of the spinal cord also connect to hypothalamic nucleispecifically the posterior and lateral areas, and the locus ceruleus (Campese and Kogosov, 1995; Jansen et al., 1995). Together these data suggest that long-term RDN results may possibly occur due to remodeling of crucial brainstem sites and both SG.

\section{CONCLUSION AND FUTURE RESEARCH DIRECTIONS}

Sympathetic nervous system activation is a key feature of CKD and ESRD and causally linked to adverse cardiac consequences. The renal nerves, in particular, appear to be essential mediators and can now be targeted selectively. Data from small and mostly uncontrolled studies in relevant cohorts support the concept that targeting the renal nerves directly may confer benefit beyond blood pressure lowering. This therapeutic approach may beneficially impact on the CV sequelae commonly encountered in CKD and ESRD such as SCD and VAs. Clearly, appropriately designed larger-scale studies in both CKD and ESRD cohorts are necessary to substantiate these preliminary findings and to demonstrate the potential clinical utility of targeting sympathetic overactivity to decrease the high morbidity and mortality related to $\mathrm{HF}$ and cardiac arrhythmias in this high-risk population.

\section{AUTHOR CONTRIBUTIONS}

$\mathrm{MK}, \mathrm{JH}$, and MS wrote the first draft of the manuscript. JN, LG, RC, and VM wrote sections of the manuscript. All authors contributed to the manuscript revision, read, and approved the submitted version.

refractory ventricular arrhythmias. JACC Cardiovasc. Interv. 8, 984-990. doi: 10.1016/j.jcin.2015.03.012

Barajas, L., Liu, L., Powers, K. (1992). Anatomy of the renal innervation: intrarenal aspects and ganglia of origin. Can. J. Physiol. Pharmacol. 70, 735-749. doi: 10.1139/y92-098

Barnett, A. H., Bain, S. C., Bouter, P., Karlberg, B., Madsbad, S., Jervell, J., et al. (2004). Angiotensin-receptor blockade versus converting-enzyme inhibition in type 2 diabetes and nephropathy. N. Engl. J. Med. 351, 1952-1961. doi: 10.1056/nejmoa042274

Bercik, P., Park, A. J., Sinclair, D., Khoshdel, A., Lu, J., Huang, X., et al. (2011). The anxiolytic effect of Bifidobacterium longum NCC3001 involves vagal pathways 
for gut-brain communication. Neurogastroenterol. Motil. 23, 1132-1139. doi: 10.1111/j.1365-2982.2011.01796.x

Bleyer, A. J., Hartman, J., Brannon, P. C., Reeves-Daniel, A., Satko, S. G., Russell, G. (2006). Characteristics of sudden death in hemodialysis patients. Kidney Int. 69, 2268-2273. doi: 10.1038/sj.ki.5000446

Bleyer, A. J., Russell, G. B., Satko, S. G. (1999). Sudden and cardiac death rates in hemodialysis patients. Kidney Int. 55, 1553-1559. doi: 10.1046/j.1523-1755. 1999.00391.x

Bramlett, H. M., Dietrich, W. D. (2007). Progressive damage after brain and spinal cord injury: pathomechanisms and treatment strategies. Prog. Brain Res. 161, 125-141. doi: 10.1016/s0079-6123(06)61009-1

Brandt, M. C., Mahfoud, F., Reda, S., Schirmer, S. H., Erdmann, E., Bohm, M., et al. (2012). Renal sympathetic denervation reduces left ventricular hypertrophy and improves cardiac function in patients with resistant hypertension. J. Am. Coll. Cardiol. 59, 901-909. doi: 10.1016/j.jacc.2011.11.034

Bravo, J. A., Forsythe, P., Chew, M. V., Escaravage, E., Savignac, H. M., Dinan, T. G., et al. (2011). Ingestion of Lactobacillus strain regulates emotional behavior and central GABA receptor expression in a mouse via the vagus nerve. Proc. Natl. Acad. Sci. U.S.A. 108, 16050-16055. doi: 10.1073/pnas.110299 9108

Briet, M., Collin, C., Karras, A., Laurent, S., Bozec, E., Jacquot, C., et al. (2011). Arterial remodeling associates with CKD progression. J. Am. Soc. Nephrol. 22, 967-974. doi: 10.1681/ASN.2010080863

Bristow, M. R., Saxon, L. A., Boehmer, J., Krueger, S., Kass, D. A., De Marco, T., et al. (2004). Cardiac-resynchronization therapy with or without an implantable defibrillator in advanced chronic heart failure. N. Engl. J. Med. 350, 2140-2150.

Brotman, D. J., Bash, L. D., Qayyum, R., Crews, D., Whitsel, E. A., Astor, B. C., et al. (2010). Heart rate variability predicts ESRD and CKD-related hospitalization. J. Am. Soc. Nephrol. 21, 1560-1570. doi: 10.1681/ASN.2009111112

Burton, J. O., Jefferies, H. J., Selby, N. M., McIntyre, C. W. (2009). Hemodialysisinduced cardiac injury: determinants and associated outcomes. Clin. J. Am. Soc. Nephrol. 4, 914-920. doi: 10.2215/CJN.03900808

Campese, V. M., Kogosov, E. (1995). Renal afferent denervation prevents hypertension in rats with chronic renal failure. Hypertension 25(4 Pt 2):878882. doi: 10.1161/01.hyp.25.4.878

Campese, V. M., Mitra, N., Sandee, D. (2006). Hypertension in renal parenchymal disease: Why is it so resistant to treatment? Kidney Int. 69, 967-973. doi: 10.1038/sj.ki.5000177

Carnagarin, R., Matthews, V., Zaldivia, M. T. K., Peter, K., Schlaich, M. P. (2019). The bidirectional interaction between the sympathetic nervous system and immune mechanisms in the pathogenesis of hypertension. Brit. J. Pharmacol. 176, 1839-1852. doi: 10.1111/bph.14481

Ceia, F., Fonseca, C., Mota, T., Morais, H., Matias, F., de Sousa, A., et al. (2002). Prevalence of chronic heart failure in Southwestern Europe: the EPICA study. Eur. J. Heart Fail. 4, 531-539. doi: 10.1016/s1388-9842(02)00034-x

Cerasola, G., Nardi, E., Mule, G., Palermo, A., Cusimano, P., Guarneri, M., et al. (2010). Left ventricular mass in hypertensive patients with mild-to-moderate reduction of renal function. Nephrology 15, 203-210. doi: 10.1111/j.1440-1797. 2009.01178.x

Cioffi, G., Tarantini, L., Frizzi, R., Stefenelli, C., Russo, T. E., Selmi, A., et al. (2011). Chronic kidney disease elicits excessive increase in left ventricular mass growth in patients at increased risk for cardiovascular events. J. Hypertens. 29, 565-573. doi: 10.1097/HJH.0b013e3283424188

Converse, R. L., Jacobsen, T. N., Toto, R. D., Jost, C. M. T., Cosentino, F., Fouadtarazi, F., et al. (1992). Sympathetic overactivity in patients with chronic-renal-failure. N. Engl. J. Med. 327, 1912-1918. doi: 10.1056/ nejm199212313272704

da Silva, P. M., Aguiar, C. (2017). Sacubitril/valsartan: an important piece in the therapeutic puzzle of heart failure. Rev. Portuguesa Cardiol. 36, 655-668. doi: 10.1016/j.repc.2016.11.013

Delacroix, S., Chokka, R. G., Sahay, S., Nelson, A. J., Nimmo, J., Wong, D. T., et al. (2014). Renal sympathetic denervation increases renal artery blood flow: a serial mri study in resistant hypertension. Circulation 130(Suppl_2):A18099

Deo, R., Lin, F., Vittinghoff, E., Tseng, Z. H., Hulley, S. B., Shlipak, M. G. (2008). Kidney dysfunction and sudden cardiac death among women with coronary heart disease. Hypertension 51, 1578-1582. doi: 10.1161/ HYPERTENSIONAHA.107.103804
Deo, R., Sotoodehnia, N., Katz, R., Sarnak, M. J., Fried, L. F., Chonchol, M., et al. (2010). Cystatin C and sudden cardiac death risk in the elderly. Circ. Cardiovasc. Qual. Outcomes. 3, 159-164. doi: 10.1161/CIRCOUTCOMES.109.875369

DiBona, G. F., Kopp, U. C. (1997). Neural control of renal function. Physiol. Rev. 77, 75-197. doi: 10.1152/physrev.1997.77.1.75

Dinan, T. G., Cryan, J. F. (2017). Gut-brain axis in 2016: Brain-gut-microbiota axis - mood, metabolism and behaviour. Nat. Rev. Gastroenterol. Hepatol. 14, 69-70. doi: 10.1038/nrgastro.2016.200

Doltra, A., Messroghli, D., Stawowy, P., Hassel, J. H., Gebker, R., Leppanen, O., et al. (2014). Potential reduction of interstitial myocardial fibrosis with renal denervation. J. Am. Heart Assoc. 3:e001353. doi: 10.1161/JAHA.114.001353

Dorr, O., Liebetrau, C., Mollmann, H., Gaede, L., Troidl, C., Morczeck, K., et al. (2015). Influence of Renal Sympathetic Denervation on Cardiac Extracellular Matrix Turnover and Cardiac Fibrosis. Am. J. Hypertens. 28, 1285-1292. doi: 10.1093/ajh/hpv020

Drukker, J., Groen, G. J., Boekelaar, A. B., Baljet, B. (1987). The extrinsic innervation of the rat kidney. Clin. Exp. Hypertens. A. 9(Suppl 1), 15-31.

Esler, M., Lambert, G., Brunner-La Rocca, H. P., Vaddadi, G., Kaye, D. (2003). Sympathetic nerve activity and neurotransmitter release in humans: translation from pathophysiology into clinical practice. Acta Physiol. Scand. 177, 275-284. doi: 10.1046/j.1365-201x.2003.01089.x

Evenepoel, P., Poesen, R., Meijers, B. (2017). The gut-kidney axis. Pediatr. Nephrol. 32, 2005-2014. doi: 10.1007/s00467-016-3527-x

Ferguson, M., Ryan, G. B., Bell, C. (1986). Localization of sympathetic and sensory neurons innervating the rat kidney. J. Auton. Nerv. Syst. 16, 279-288. doi: 10.1016/0165-1838(86)90034-2

Foley, R. N., Gilbertson, D. T., Murray, T., Collins, A. J. (2011). Long interdialytic interval and mortality among patients receiving hemodialysis. N. Engl. J. Med. 365, 1099-1107. doi: 10.1056/nejmoa1 103313

Franciosi, S., Perry, F. K. G., Roston, T. M., Armstrong, K. R., Claydon, V. E., Sanatani, S. (2017). The role of the autonomic nervous system in arrhythmias and sudden cardiac death. Auton. Neurosci. 205, 1-11. doi: 10.1016/j.autneu. 2017.03.005

Friedman, A. N., Groh, W. J., Das, M. (2007). A pilot study in hemodialysis of an electrophysiological tool to measure sudden cardiac death risk. Clin. Nephrol. 68, 159-164. doi: 10.5414/cnp68159

Fukuda, K., Kanazawa, H., Aizawa, Y., Ardell, J. L., Shivkumar, K. (2015). Cardiac innervation and sudden cardiac death. Circ. Res. 116, 2005-2019. doi: 10.1161/ CIRCRESAHA.116.304679

Ganesh, S. K., Stack, A. G., Levin, N. W., Hulbert-Shearon, T., Port, F. K. (2001). Association of elevated serum $\mathrm{PO}(4), \mathrm{Ca} \times \mathrm{PO}(4)$ product, and parathyroid hormone with cardiac mortality risk in chronic hemodialysis patients. J. Am. Soc. Nephrol. 12, 2131-2138.

Garthwaite, J., Boulton, C. L. (1995). Nitric oxide signaling in the central nervous system. Annu. Rev. Physiol. 57, 683-706. doi: 10.1146/annurev.physiol.57.1.683

Gattone, V. H. II, Marfurt, C. F., Dallie, S. (1986). Extrinsic innervation of the rat kidney: a retrograde tracing study. Am. J. Physiol. 250(2 Pt 2), F189-F196.

Goldenberg, I., Moss, A. J., McNitt, S., Zareba, W., Andrews, M. L., Hall, W. J., et al. (2006). Relations among renal function, risk of sudden cardiac death, and benefit of the implanted with ischemic left cardiac defibrillator in patients ventricular dysfunction. Am. J. Cardiol. 98, 485-490. doi: 10.1016/j.amjcard. 2006.03.025

Grassi, G. (2009). Assessment of sympathetic cardiovascular drive in human hypertension: achievements and perspectives. Hypertension 54, 690-697. doi: 10.1161/HYPERTENSIONAHA.108.119883

Grassi, G. (2010). Sympathetic neural activity in hypertension and related diseases. Am. J. Hypertens. 23, 1052-1060. doi: 10.1038/ajh.2010.154

Grassi, G., Bertoli, S., Seravalle, G. (2012). Sympathetic nervous system: role in hypertension and in chronic kidney disease. Curr. Opin. Nephrol. Hypertens. 21, 46-51. doi: 10.1097/MNH.0b013e32834db45d

Grassi, G., Colombo, M., Seravalle, G., Spaziani, D., Mancia, G. (1998). Dissociation between muscle and skin sympathetic nerve activity in essential hypertension, obesity, and congestive heart failure. Hypertension 31, 64-67. doi: 10.1161/01. hyp.31.1.64

Green, D., Batchvarov, V., Wijesekara, C., Kalra, P. A., Camm, A. J. (2012). Dialysisdependent changes in ventricular repolarization. Pacing Clin. Electrophys. 35, 703-710. doi: 10.1111/j.1540-8159.2012.03364.x 
Gruppo Emodialisi E Patologie Cardiovascolari, (1988). Multicentre crosssectional study of ventricular arrhythmias in chronically haemodialysed patients. gruppo emodialisi e patologie cardiovasculari. Lancet 2, 305-309. doi: 10.1016/s0140-6736(88)92357-4

Guertzenstein, P. G., Silver, A. (1974). Fall in blood pressure produced from discrete regions of the ventral surface of the medulla by glycine and lesions. J. Physiol. 242, 489-503. doi: 10.1113/jphysiol.1974.sp010719

Haider, A. W., Larson, M. G., Benjamin, E. J., Levy, D. (1998). Increased left ventricular mass and hypertrophy are associated with increased risk for sudden death. J. Am. Coll. Cardiol. 32, 1454-1459. doi: 10.1016/s0735-1097(98)00 407-0

Hausberg, M., Grassi, G. (2007). Mechanisms of sympathetic overactivity in patients with chronic renal failure: a role for chemoreflex activation? J. Hypertens. 25, 47-49. doi: 10.1097/hjh.0b013e3280119286

Hering, D., Lambert, E. A., Marusic, P., Walton, A. S., Krum, H., Lambert, G W., et al. (2013). Substantial reduction in single sympathetic nerve firing after renal denervation in patients with resistant hypertension. Hypertension. 61, 457-464. doi: 10.1161/HYPERTENSIONAHA.111.00194

Hering, D., Mahfoud, F., Walton, A. S., Krum, H., Lambert, G. W., Lambert, E. A., et al. (2012). Renal denervation in moderate to severe CKD. J. Am. Soc. Nephrol. 23, 1250-1257. doi: 10.1681/ASN.2011111062

Herzog, C. A., Li, S., Weinhandl, E. D., Strief, J. W., Collins, A. J., Gilbertson, D. T. (2005). Survival of dialysis patients after cardiac arrest and the impact of implantable cardioverter defibrillators. Kidney Int. 68, 818-825. doi: 10.1016/ s0085-2538(15)50904-6

Herzog, C. A., Ma, J. Z., Collins, A. J. (1998). Poor long-term survival after acute myocardial infarction among patients on long-term dialysis. N. Engl. J. Med. 339, 799-805. doi: 10.1056/nejm199809173391203

Hopper, I., Gronda, E., Hoppe, U. C., Rundqvist, B., Marwick, T. H., Shetty, S., et al. (2017). Sympathetic response and outcomes following renal denervation in patients with chronic heart failure: 12-month outcomes from the symplicity HF feasibility study. J. Cardiac. Failure. 23, 702-707. doi: 10.1016/j.cardfail. 2017.06.004

Hu, M. C., Shi, M. J., Zhang, J. N., Quinones, H., Griffith, C., Kuro-o, M., et al. (2011). Klotho deficiency causes vascular calcification in chronic kidney disease. J. Am. Soc. Nephrol. 22, 124-136. doi: 10.1681/asn.2009121311

Hunter, J. J., Chien, K. R. (1999). Signaling pathways for cardiac hypertrophy and failure. N Engl J Med. 341, 1276-1283. doi: 10.1056/nejm19991021341 1706

Jansen, A. S., Wessendorf, M. W., and Loewy, A. D. (1995). Transneuronal labeling of CNS neuropeptide and monoamine neurons after pseudorabies virus injections into the stellate ganglion. Brain Res. 683, 1-24. doi: 10.1016/00068993(95)00276-v

Josefsdottir, K. S., Baldridge, M. T., Kadmon, C. S., King, K. Y. (2017). Antibiotics impair murine hematopoiesis by depleting the intestinal microbiota. Blood 129, 729-739. doi: 10.1182/blood-2016-03-708594

Jourde-Chiche, N., Dou, L., Cerini, C., Dignat-George, F., Vanholder, R., Brunet, P. (2009). Protein-Bound Toxins-Update 2009. Semin. Dialysis. 22, 334-339. doi: 10.1111/j.1525-139X.2009.00576.x

Karbach, S. H., Schonfelder, T., Brandao, I., Wilms, E., Hormann, N., Jackel, S., et al. (2016). Gut microbiota promote angiotensin ii-induced arterial hypertension and vascular dysfunction. J. Am. Heart Assoc. 5:e003698. doi: 10.1161/JAHA. 116.003698

Kimura, Y., Hirooka, Y., Sagara, Y., Ito, K., Kishi, T., Shimokawa, H., et al. (2005). Overexpression of inducible nitric oxide synthase in rostral ventrolateral medulla causes hypertension and sympathoexcitation via an increase in oxidative stress. Circ. Res. 96, 252-260. doi: 10.1161/01.res.0000152965. $75127.9 \mathrm{~d}$

Kingwell, B. A., Waddell, T. K., Medley, T. L., Cameron, J. D., Dart, A. M. (2002). Large artery stiffness predicts ischemic threshold in patients with coronary artery disease. J. Am. Coll. Cardiol. 40, 773-779. doi: 10.1016/s0735-1097(02) 02009-0

Kiuchi, M. G., and Mion, D. (2016). Chronic kidney disease and risk factors responsible for sudden cardiac death: a whiff of hope? Kidney Res. Clin. Pract. 35, 3-9. doi: 10.1016/j.krcp.2015.11.003

Kiuchi, M. G., Chen, S J., Andrea, B. R., Kiuchi, T., Carreira, M. A. M. D., Graciano, M. L., et al. (2014). Renal sympathetic denervation in patients with hypertension and chronic kidney disease: does improvement in renal function follow blood pressure control? J. Clin. Hypertens. 16, 794-800. doi: 10.1111/jch. 12415

Kiuchi, M. G., Chen, S., Paz, L. M. R., Purerfellner, H. (2017). Renal sympathetic denervation guided by renal nerve stimulation to treat ventricular arrhythmia in CKD patients with ICD. Oncotarget 8, 37296-37307. doi: 10.18632/ oncotarget.16278

Kiuchi, M. G., Graciano, M. L., Carreira, M. A. M. D., Kiuchi, T., Chen, S., Andrea, B. R., et al. (2016a). Effects of renal sympathetic denervation in left ventricular hypertrophy in CKD refractory hypertensive patients. Int. J. Cardiol. 202, 121-123. doi: 10.1016/j.ijcard.2015.08.206

Kiuchi, M. G., Maia, G. L. M., Carreira, M. A. M. D., Kiuchi, T., Chen, S. C., Andrea, B. R., et al. (2013). Effects of renal denervation with a standard irrigated cardiac ablation catheter on blood pressure and renal function in patients with chronic kidney disease and resistant hypertension. Eur. Heart J. 34, 2114-2121. doi: 10.1093/eurheartj/eht200

Kiuchi, M. G., Mion, D., Graciano, M. L., Carreira, M. A. M. D., Kiuchi, T., Chen, S. J., et al. (2016b). Proof of concept study: improvement of echocardiographic parameters after renal sympathetic denervation in CKD refractory hypertensive patients. Int. J. Cardiol. 207, 6-12. doi: 10.1016/j.ijcard.2016. 01.088

Krittayaphong, R., Bhuripanyo, K., Punlee, K., Kangkagate, C., Chaithiraphan, S. (2002). Effect of atenolol on symptomatic ventricular arrhythmia without structural heart disease: a randomized placebo-controlled study. Am. Heart J. 144:e10.

Krum, H., Schlaich, M. P., Sobotka, P. A., Bohm, M., Mahfoud, F., Rocha-Singh, K., et al. (2014). Percutaneous renal denervation in patients with treatmentresistant hypertension: final 3-year report of the Symplicity HTN-1 study. Lancet 383, 622-629. doi: 10.1016/S0140-6736(13)62192-3

Krum, H., Schlaich, M., Whitbourn, R., Sobotka, P. A., Sadowski, J., Bartus, K., et al. (2009). Catheter-based renal sympathetic denervation for resistant hypertension: a multicentre safety and proof-of-principle cohort study. Lancet 373, 1275-1281. doi: 10.1016/S0140-6736(09)60566-3

Kruzan, R. M., Herzog, C. A., Wu, A., Sang, Y., Parekh, R. S., Matsushita, K., et al. (2016). Association of NTproBNP and cTnI with outpatient sudden cardiac death in hemodialysis patients: the choices for healthy outcomes in caring for ESRD (CHOICE) study. BMC Nephrol. 17:18. doi: 10.1186/s12882-016-0230-x

Kumagai, H., Oshima, N., Matsuura, T., Iigaya, K., Imai, M., Onimaruv, H., et al. (2012). Importance of rostral ventrolateral medulla neurons in determining efferent sympathetic nerve activity and blood pressure. Hypertens. Res. 35, 132-141. doi: 10.1038/hr.2011.208

Kumar, P., Savant, K., Prabhu, R. A. (2016). Timing and characteristics of sudden death in a patient population on hemodialysis. Value Health 19:A74.

Kusumoto, F. M., Bailey, K. R., Chaouki, A. S., Deshmukh, A. J., Gautam, S., Kim, R. J., et al. (2018). Systematic review for the 2017 AHA/ACC/HRS Guideline for management of patients with ventricular arrhythmias and the prevention of sudden cardiac death: a report of the american college of cardiology/american heart association task force on clinical practice guidelines and the heart rhythm society. J. Am. Coll. Cardiol. 72, 1653-1676.

Lau, D. H., Mackenzie, L., Kelly, D. J., Psaltis, P. J., Brooks, A. G., Worthington, M., et al. (2010). Hypertension and atrial fibrillation: evidence of progressive atrial remodeling with electrostructural correlate in a conscious chronically instrumented ovine model. Heart Rhythm. 7, 1282-1290. doi: 10.1016/j.hrthm. 2010.05.010

Levey, A. S., Beto, J. A., Coronado, B. E., Eknoyan, G., Foley, R. N., Kasiske, B. L., et al. (1998). Controlling the epidemic of cardiovascular disease in chronic renal disease: what do we know? What do we need to learn? Where do we go from here? Am. J. Kidney Dis. 32, 853-906.

Levin, A., Thompson, C. R., Ethier, J., Carlisle, E. J., Tobe, S., Mendelssohn, D., et al. (1999). Left ventricular mass index increase in early renal disease: impact of decline in hemoglobin. Am. J. Kidney Dis. 34, 125-134. doi: 10.1016/s02726386(99)70118-6

Lorincz, I., Matyus, J., Zilahi, Z., Kun, C., Karanyi, Z., Kakuk, G. (1999). QT dispersion in patients with end-stage renal failure and during hemodialysis. J. Am. Soc. Nephrol. 10, 1297-1302.

Lundin, S., Ricksten, S. E., Thoren, P. (1984). Renal sympathetic activity in spontaneously hypertensive rats and normotensive controls, as studied by three different methods. Acta Physiol. Scand. 120, 265-272. doi: 10.1111/j.1748-1716. 1984.tb00133.x 
Luo, D., Zhang, X., Lu, C. Z. (2013). Renal sympathetic denervation for the treatment of resistant hypertension with chronic renal failure: first-in-man experience. Chin. Med. J. 126, 1392-1393.

Mahfoud, F., Tunev, S., Ewen, S., Cremers, B., Ruwart, J., Schulz-Jander, D., et al. (2015). Impact of lesion placement on efficacy and safety of catheter-based radiofrequency renal denervation. J. Am. Coll. Cardiol. 66, 1766-1775. doi: 10.1016/j.jacc.2015.08.018

Mahfoud, F., Urban, D., Teller, D., Linz, D., Stawowy, P., Hassel, J. H., et al. (2014). Effect of renal denervation on left ventricular mass and function in patients with resistant hypertension: data from a multi-centre cardiovascular magnetic resonance imaging trial. Eur. Heart J. 35:2224b-2231b. doi: 10.1093/eurheartj/ ehu093

Mahmoodi, B. K., Matsushita, K., Woodward, M., Blankestijn, P. J., Cirillo, M., Ohkubo, T., et al. (2012). Associations of kidney disease measures with mortality and end-stage renal disease in individuals with and without hypertension: a meta-analysis. Lancet 380, 1649-1661. doi: 10.1016/S01406736(12)61272-0

Mall, G., Huther, W., Schneider, J., Lundin, P., Ritz, E. (1990). Diffuse intermyocardiocytic fibrosis in uraemic patients. Nephrol. Dial. Transplant. 5, 39-44. doi: 10.1093/ndt/5.1.39

Mark, P. B., Johnston, N., Groenning, B. A., Foster, J. E., Blyth, K. G., Martin, T. N., et al. (2006). Redefinition of uremic cardiomyopathy by contrast-enhanced cardiac magnetic resonance imaging. Kidney Int. 69, 1839-1845. doi: 10.1038/ sj.ki.5000249

Martinez, A. W., Recht, N. S., Hostetter, T. H., Meyer, T. W. (2005). Removal of P-cresol sulfate by hemodialysis. J. Am. Soc. Nephrol. 16, 3430-3436. doi: 10.1681/asn.2005030310

McGrath, B. P., Ledingham, J. G., Benedict, C. R. (1978). Catecholamines in peripheral venous plasma in patients on chronic haemodialysis. Clin. Sci. Mol. Med. 55, 89-96. doi: 10.1042/cs0550089

McLellan, A. J., Schlaich, M. P., Taylor, A. J., Prabhu, S., Hering, D., Hammond, L., et al. (2015). Reverse cardiac remodeling after renal denervation: atrial electrophysiologic and structural changes associated with blood pressure lowering. Heart Rhythm. 12, 982-990. doi: 10.1016/j.hrthm.2015.01.039

McMurray, J. J., Packer, M., Desai, A. S., Gong, J., Lefkowitz, M. P., Rizkala, A. R., et al. 2014. Angiotensin-neprilysin inhibition versus enalapril in heart failure. N. Engl. J. Med. 371, 993-1004.

Meckler, R. L., Weaver, L. C. (1984). Comparison of the distributions of renal and splenic neurons in sympathetic ganglia. J. Auton Nerv. Syst. 11, 189-200. doi: 10.1016/0165-1838(84)90076-6

Morales, M. A., Gremigni, C., Dattolo, P., Piacenti, M., Cerrai, T., Fazi, A., et al. (1998). Signal-averaged ECG abnormalities in haemodialysis patients. Role of dialysis. Nephrol. Dialysis Trans. 13, 668-673. doi: 10.1093/ndt/13.3.668

Moran, A., Katz, R., Jenny, N. S., Astor, B., Bluemke, D. A., Lima, J. A. C., et al. (2008). Left ventricular hypertrophy in mild and moderate reduction in kidney function determined using cardiac magnetic resonance imaging and cystatin c: the multi-ethnic study of atherosclerosis (MESA). Am. J. Kidney Dis. 52, 839-848. doi: 10.1053/j.ajkd.2008.06.012

Morris, S. T. W., Galiatsou, E., Stewart, G. A., Rodger, R. S. C., Jardine, A. G. (1999). QT dispersion before and after hemodialysis. J. Am. Soc. Nephrol. 10, 160-163.

Mulder, J., Hokfelt, T., Knuepfer, M. M., Kopp, U. C. (2013). Renal sensory and sympathetic nerves reinnervate the kidney in a similar time-dependent fashion after renal denervation in rats. Am. J. Physiol. Regul. Integr. Comp. Physiol. 304, R675-R682. doi: 10.1152/ajpregu.00599.2012

Neumann, J., Ligtenberg, G., Klein, I. I., Koomans, H. A., Blankestijn, P. J. (2004). Sympathetic hyperactivity in chronic kidney disease: pathogenesis, clinical relevance, and treatment. Kidney Int. 65, 1568-1576. doi: 10.1111/j.1523-1755. 2004.00552.x

$\mathrm{Ng}$, G. A. (2016). Neuro-cardiac interaction in malignant ventricular arrhythmia and sudden cardiac death. Auton. Neurosci. 199, 66-79. doi: 10.1016/j.autneu. 2016.07.001

Ott, C., Mahfoud, F., Schmid, A., Ditting, T., Veelken, R., Ewen, S., et al. (2014). Improvement of albuminuria after renal denervation Int. J. Cardiol. 173, 311-315 doi: 10.1016/j.ijcard.2014.03.017

Pai, A. S., Giachelli, C. M. (2010). Matrix remodeling in vascular calcification associated with chronic kidney disease. J. Am. Soc. Nephrol. 21, 1637-1640. doi: $10.1681 /$ asn.2010040349
Paoletti, E., Bellino, D., Cassottana, P., Rolla, D., Cannella, G. (2005). Left ventricular hypertrophy in nondiabetic predialysis CKD. Am. J. Kidney Dis. 46, 320-327. doi: 10.1053/j.ajkd.2005.04.031

Parekh, R. S., Carroll, C. E., Wolfe, R. A., Port, F. K. (2002). Cardiovascular mortality in children and young adults with end-stage kidney disease. J. Pediatr. 141, 191-197. doi: 10.1067/mpd.2002.125910

Parekh, R. S., Plantinga, L. C., Kao, W. H., Meoni, L. A., Jaar, B. G., Fink, N. E., et al. (2008). The association of sudden cardiac death with inflammation and other traditional risk factors. Kidney Int. 74, 1335-1342. doi: 10.1038/ki.2008.449

Patel, R. K., Mark, P. B., Halliday, C., Steedman, T., Dargie, H. J., Cobbe, S M., et al. (2011). Microvolt T-wave alternans in end-stage renal disease patientsassociations with uremic cardiomyopathy. Clin. J. Am. Soc. Nephrol. 6, 519-527. doi: $10.2215 / C J N .06370710$

Paton, J. F., Raizada, M. K. (2010). Neurogenic hypertension. Exp. Physiol. 95, 569-571. doi: 10.1113/expphysiol.2009.047282

Perl, J., Chan, C. T. (2006). Timing of sudden death relative to the hemodialysis procedure. Nat. Clin. Pract. Nephrol. 2, 668-669. doi: 10.1038/ncpneph0345

Perlini, S., Palladini, G., Ferrero, I., Tozzi, R., Fallarini, S., Facoetti, A., et al. (2005). Sympathectomy or doxazosin, but not propranolol, blunt myocardial interstitial fibrosis in pressure-overload hypertrophy. Hypertension 46, 1213-1218. doi: 10.1161/01.hyp.0000185689.65045.4c

Perticone, F., Maio, R., Perticone, M., Sciacqua, A., Shehaj, E., Naccarato, P., et al. (2010). Endothelial dysfunction and subsequent decline in glomerular filtration rate in hypertensive patients. Circulation 122, 379-384. doi: 10.1161/ CIRCULATIONAHA.110.940932

Perticone, F., Maio, R., Tripepi, G., Zoccali, C. (2004). Endothelial dysfunction and mild renal insufficiency in essential hypertension. Circulation 110, 821-825. doi: 10.1161/01.cir.0000138745.21879.27

Pilowsky, P., Llewellyn-Smith, I. J., Minson, J., Chalmers, J. (1992). Sympathetic preganglionic neurons in rabbit spinal cord that project to the stellate or the superior cervical ganglion. Brain Res. 577, 181-188. doi: 10.1016/00068993(92)90272-b

Priori, S. G., Blomstrom-Lundqvist, C., Mazzanti, A., Blom, N., Borggrefe, M., Camm, J., et al. (2016). [2015 ESC Guidelines for the management of patients with ventricular arrhythmias and the prevention of sudden cardiac death. the task force for the management of patients with ventricular arrhythmias and the prevention of sudden cardiac death of the european society of cardiology]. G. Ital. Cardiol. 17, 108-170.

Prystowsky, E. N., Padanilam, B. J., Joshi, S., Fogel, R. I. (2012). Ventricular arrhythmias in the absence of structural heart disease. J. Am. Coll. Cardiol. 59, 1733-1744. doi: 10.1016/j.jacc.2012.01.036

Pun, P. H., Smarz, T. R., Honeycutt, E. F., Shaw, L. K., Al-Khatib, S. M., Middleton, J. P. (2009). Chronic kidney disease is associated with increased risk of sudden cardiac death among patients with coronary artery disease. Kidney Int. 76, 652-658. doi: 10.1038/ki.2009.219

Reinier, K., Dervan, C., Singh, T., Uy-Evanado, A., Lai, S. H., Gunson, K., et al. (2011). Increased left ventricular mass and decreased left ventricular systolic function have independent pathways to ventricular arrhythmogenesis in coronary artery disease. Heart Rhythm. 8, 1177-1182. doi: 10.1016/j.hrthm. 2011.02.037

Remo, B. F., Preminger, M., Bradfield, J., Mittal, S., Boyle, N., Gupta, A., et al. (2014). Safety and efficacy of renal denervation as a novel treatment of ventricular tachycardia storm in patients with cardiomyopathy. Heart Rhythm. 11, 541-546. doi: 10.1016/j.hrthm.2013.12.038

Roes, S. D., Borleffs, C. J., van der Geest, R. J., Westenberg, J. J., Marsan, N. A., Kaandorp, T. A., et al. (2009). Infarct tissue heterogeneity assessed with contrast-enhanced MRI predicts spontaneous ventricular arrhythmia in patients with ischemic cardiomyopathy and implantable cardioverterdefibrillator. Circ. Cardiovasc. Imag. 2, 183-190. doi: 10.1161/CIRCIMAGING. 108.826529

Rooks, M. G., Garrett, W. S. (2016). Gut microbiota, metabolites and host immunity. Nat. Rev. Immunol. 16, 341-352. doi: 10.1038/nri.2016.42

Sabatino, A., Regolisti, G., Brusasco, I., Cabassi, A., Morabito, S., Fiaccadori, E. (2015). Alterations of intestinal barrier and microbiota in chronic kidney disease. Nephrol. Dial. Transplant. 30, 924-933. doi: 10.1093/ndt/gfu287

Santisteban, M. M., Ahmari, N., Carvajal, J. M., Zingler, M. B., Qi, Y., Kim, S., et al. (2015). Involvement of bone marrow cells and neuroinflammation 
in hypertension. Circ. Res. 117, 178-191. doi: 10.1161/CIRCRESAHA.117. 305853

Saxon, L. A., Bristow, M. R., Boehmer, J., Krueger, S., Kass, D. A., De Marco, T., et al. (2006). Predictors of sudden cardiac death and appropriate shock in the Comparison of Medical Therapy, Pacing, and Defibrillation in Heart Failure (COMPANION) Trial. Circulation 114, 2766-2772. doi: 10.1161/ circulationaha.106.642892

Schlaich, M. P., Bart, B., Hering, D., Walton, A., Marusic, P., Mahfoud, F., et al. (2013). Feasibility of catheter-based renal nerve ablation and effects on sympathetic nerve activity and blood pressure in patients with endstage renal disease. Int. J. Cardiol. 168, 2214-2220. doi: 10.1016/j.ijcard.2013. 01.218

Schlaich, M. P., Sobotka, P. A., Krum, H., Lambert, E., Esler, M. D. (2009b). Renal sympathetic-nerve ablation for uncontrolled hypertension. N. Engl. J. Med. 361, 932-934. doi: 10.1056/nejmc0904179

Schlaich, M. P., Sobotka, P. A., Krum, H., Whitbourn, R., Walton, A., and Esler, M. D. (2009c). Renal denervation as a therapeutic approach for hypertension novel implications for an old concept. Hypertension 54, 1195-1201. doi: 10. 1161/hypertensionaha.109.138610

Schlaich, M. P., Socratous, F., Hennebry, S., Eikelis, N., Lambert, E. A., Straznicky, N., et al. (2009a). Sympathetic activation in chronic renal failure. J. Am. Soc. Nephrol. 20, 933-939.

Schlieper, G., Aretz, A., Verberckmoes, S. C., Kruger, T., Behets, G. J., Ghadimi, R., et al. (2010). Ultrastructural analysis of vascular calcifications in uremia. J. Am. Soc. Nephrol. 21, 689-696. doi: 10.1681/ASN.2009080829

Schmidt, A., Azevedo, C. F., Cheng, A., Gupta, S. N., Bluemke, D. A., Foo, T. K., et al. (2007). Infarct tissue heterogeneity by magnetic resonance imaging identifies enhanced cardiac arrhythmia susceptibility in patients with left ventricular dysfunction. Circulation. 115, 2006-2014. doi: 10.1161/ circulationaha.106.653568

Schmieder, R. E., Hilgers, K. F., Schlaich, M. P., Schmidt, B. M. (2007). Reninangiotensin system and cardiovascular risk. Lancet 369, 1208-1219.

Schmieder, R. E., Mahfoud, F., Schmid, A., Ditting, T., Veelken, R., Ewen, S., et al. (2014). Improvement of albuminuria after renal denervation. J. Am. Coll. Cardiol. 63:A2055-A. doi: 10.1016/j.ijcard.2014.03.017

Schroeder, A. P., Kristensen, B. O., Nielsen, C. B., Pedersen, E. B. (1997). Heart function in patients with chronic glomerulonephritis and mildly to moderately impaired renal function. An echocardiographic study. Blood Press. 6, 286-293. doi: 10.3109/08037059709062084

Secemsky, E. A., Verrier, R. L., Cooke, G., Ghossein, C., Subacius, H., Manuchehry, A., et al. (2011). High prevalence of cardiac autonomic dysfunction and T-wave alternans in dialysis patients. Heart Rhythm. 8, 592-598. doi: 10.1016/j.hrthm. 2010.11.041

Shankland, S. J., Jefferson, J. A. (2017). A bone marrow factor contributes to kidney disease. Nat Med. 23, 13-14. doi: 10.1038/nm.4263

Shen, M. J., Zipes, D. P. (2014). Role of the autonomic nervous system in modulating cardiac arrhythmias. Circ. Res. 114, 1004-1021. doi: 10.1161/ CIRCRESAHA.113.302549

Shinohara, M. S., Fujino, F. T., Yao, S. Y., Akitsu, K. A., Koike, H. K., Yuzawa, H. Y., et al. (2017). Assessment of a novel transdermal selective B1-blocker, the bisoprolol patch, for treating frequent premature ventricular contractions in patients without structural heart disease. Eur. Heart J. 38, $170-171$.

Shroff, R., Shanahan, C. M. (2011). Klotho: an elixir of youth for the vasculature? J Am Soc Nephrol. 22, 5-7. doi: 10.1681/asn.2010111190

Sripairojthikoon, W., Wyss, J. M. (1987). Cells of origin of the sympathetic renal innervation in rat. Am. J. Physiol. 252(6 Pt 2), F957-F963.

Stevens, T. L., Rasmussen, T. E., Wei, C. M., Kinoshita, M., Matsuda, Y., Burnett, J. C. Jr. (1996). Renal role of the endogenous natriuretic peptide system in acute congestive heart failure. J. Card. Fail. 2, 119-125. doi: 10.1016/s1071-9164(96) 80030-3

Svarstad, E., Myking, O., Ofstad, J., Iversen, B. M. (2001). Sympathetic nervous system overactivity in hypertensive patients with chronic renal failure - role of upright body position. Scand. J. Urol. Nephrol. 35, 393-400. doi: 10.1080/ 003655901753224468

Symplicity, H. T. N. I., Esler, M. D., Krum, H., Sobotka, P. A., Schlaich, M. P., Schmieder, R. E., et al. (2010). Renal sympathetic denervation in patients with treatment-resistant hypertension (The Symplicity HTN-2 Trial): a randomised controlled trial. Lancet 376, 1903-1909. doi: 10.1016/S0140-6736(10)62039-9
Tinucci, T., Abrahao, S. B., Santello, J. L., Mion, D. Jr. (2001). Mild chronic renal insufficiency induces sympathetic overactivity. J. Hum. Hypertens. 15, 401-406. doi: 10.1038/sj.jhh.1001149

Tsai, W. C., Chan, Y. H., Chinda, K., Chen, Z., Patel, J., Shen, C., et al. (2017). Effects of renal sympathetic denervation on the stellate ganglion and brain stem in dogs. Heart Rhythm. 14, 255-262. doi: 10.1016/j.hrthm.2016.10.003

Ukena, C., Bauer, A., Mahfoud, F., Schreieck, J., Neuberger, H. R., Eick, C., et al. (2012). Renal sympathetic denervation for treatment of electrical storm: firstin-man experience. Clin. Res. Cardiol. 101, 63-67. doi: 10.1007/s00392-0110365-5

Ukena, C., Mahfoud, F., Ewen, S., Bollmann, A., Hindricks, G., Hoffmann, B. A. et al. (2016). Renal denervation for treatment of ventricular arrhythmias: data from an International Multicenter Registry. Clin. Res. Cardiol. 105, 873-879. doi: 10.1007/s00392-016-1012-y

United States Renal Data System (2018). 2018 USRDS Annual Data Report: Epidemiology of Kidney Disease in the United States. National Institutes of Health: Bethesda, MD.

Vanholder, R., De Smet, R., Glorieux, G., Argiles, A., Baurmeister, U., Brunet, P., et al. (2003). Review on uremic toxins: classification, concentration, and interindividual variability. Kidney Int. 63, 1934-1943. doi: 10.1046/j.1523-1755. 2003.00924.x

Vaziri, N. D. (2012). CKD impairs barrier function and alters microbial flora of the intestine: a major link to inflammation and uremic toxicity. Curr. Opin. Nephrol. Hypertens. 21, 587-592. doi: 10.1097/MNH.0b013e328358c8d5

Volpe, M., Carnovali, M., Mastromarino, V. (2016). The natriuretic peptides system in the pathophysiology of heart failure: from molecular basis to treatment. Clin. Sci. 130, 57-77. doi: 10.1042/CS20150469

Waldo, A. L., Plumb, V. J., Arciniegas, J. G., MacLean, W. A., Cooper, T. B., Priest, M. F., et al. (1983). Transient entrainment and interruption of the atrioventricular bypass pathway type of paroxysmal atrial tachycardia. a model for understanding and identifying reentrant arrhythmias. Circulation 67, 73-83. doi: 10.1161/01.cir.67.1.73

Wang, A. Y., Lam, C. W., Chan, I. H., Wang, M., Lui, S. F., Sanderson, J. E. (2010). Sudden cardiac death in end-stage renal disease patients: a 5-year prospective analysis. Hypertension 56, 210-216. doi: 10.1161/HYPERTENSIONAHA.110. 151167

Yan, A. T., Shayne, A. J., Brown, K. A., Gupta, S. N., Chan, C. W., Luu, T. M., et al. (2006). Characterization of the peri-infarct zone by contrast-enhanced cardiac magnetic resonance imaging is a powerful predictor of post-myocardial infarction mortality. Circulation 114, 32-39. doi: 10.1161/circulationaha.106. 613414

Ye, S, Ozgur,B, Campese, VM. (1997). Renal afferent impulses, the posterior hypothalamus, and hypertension in rats with chronic renal failure. Kidney Int. 51, 722-727. doi: 10.1038/ki.1997.103

Zanzinger, J. (2002). Mechanisms of action of nitric oxide in the brain stem: role of oxidative stress. Auton. Neurosci. 98, 24-27. doi: 10.1016/s1566-0702(02) 00025-5

Zipes, D. P. (2015). Antiarrhythmic therapy in 2014: contemporary approaches to treating arrhythmias. Nat. Rev. Cardiol. 12, 68-69. doi: 10.1038/nrcardio.2014.211

Zoccali, C., Mallamaci, F., Parlongo, S., Cutrupi, S., Benedetto, F. A., Tripepi, G., et al. (2002). Plasma norepinephrine predicts survival and incident cardiovascular events in patients with end-stage renal disease. Circulation 105, 1354-1359. doi: 10.1161/hc1102.105261

Conflict of Interest: MS has been an investigator in studies sponsored by Medtronic and has received speaker fees.

The remaining authors declare that the research was conducted in the absence of any commercial or financial relationships that could be construed as a potential conflict of interest.

Copyright (c) 2020 Kiuchi, Ho, Nolde, Gavidia, Carnagarin, Matthews and Schlaich. This is an open-access article distributed under the terms of the Creative Commons Attribution License (CC BY). The use, distribution or reproduction in other forums is permitted, provided the original author(s) and the copyright owner(s) are credited and that the original publication in this journal is cited, in accordance with accepted academic practice. No use, distribution or reproduction is permitted which does not comply with these terms. 